\title{
O ENSINO DE CAPOEIRA NO CHÃO DA ESCOLA: CONTRIBUIÇÕES DE UMA OFICINA NO PROGRAMA MAIS EDUCAÇÃO NA CIDADE DE SALVADOR - BA
}

\author{
Alexsandro da Silva Marques ${ }^{1}$ \\ Maria Fátima Moreira de Jesus ${ }^{2}$ \\ Emanoel Luís Roque Soares ${ }^{3}$
}

\begin{abstract}
Resumo: Este artigo apresenta algumas reflexões sobre as contribuições da oficina de capoeira desenvolvida no Programa Mais Educação em uma Escola Municipal na cidade de Salvador-Ba. Tem por objetivo analisar as contribuições da oficina de capoeira no Programa Mais Educação na aprendizagem dos estudantes. A metodologia adotada foi a pesquisa qualitativa apoiado no referencial metodológico em Pimenta (2014), Lakatos e Marconi (2009), Álvaro Pinto (1979), Manzo (1971). A pesquisa fundamentou-se nos estudos de Paulo Freire (2014; 2007; 1997), Jaqueline Moll (2012), Gomes (2012), Chauí (2008), Hélio Campos (2001), Waldeloir Rego (1968) entre outros. Os resultados evidenciam contribuições da oficina de capoeira para o desenvolvimento integral dos estudantes ao mesmo tempo em que valoriza a cultura afro-brasileira tencionando o currículo escolar.
\end{abstract}

Palavras-chave: Educação; Capoeira; Programa Mais Educação

\section{CAPOEIRA EDUCATION IN THE GROUND OF THE SCHOOL: CONTRIBUTIONS FROM AN OFFICE IN THE PROGRAM FOR MORE EDUCATION IN THE CITY OF SALVADOR - BA}

\begin{abstract}
This article presents some reflections on the contributions of the capoeira workshop developed in the More Education Program at a Municipal School in the city of Salvador-Ba. It aims to analyze the contributions of the capoeira workshop in the More Education Program in student learning. The methodology adopted was the qualitative research supported by the methodological reference in Pimenta (2014), Lakatos and Marconi (2009), Álvaro Pinto (1979), Manzo (1971). The research was based on the studies of Paulo Freire (2014, 2007, 1997), Jaqueline Moll (2012), Gomes (2012), Chauí (2008), Hélio Campos (2001), Waldeloir Rego (1968) among others. The results show the contribution of the capoeira workshop to the integral development of the students while at the same time enhancing the AfroBrazilian culture with a view to the school curriculum.
\end{abstract}

Keywords: Education; Capoeira; More Education Program

\footnotetext{
${ }^{1}$ Mestre em Educação pela Faculdade de Educação da Universidade Federal da Bahia (UFBA). Licenciado em Filosofia pela Universidade Federal do Recôncavo da Bahia (UFRB). Experiência docente em Cursos de Especialização Latu Sensu nas áreas da Psicopedagogia e Docência do Ensino Superior. Membro da Associação Nacional pela Formação dos Profissionais da Educação (ANFOPE). Integra a equipe de coordenação do núcleo Formação de Educadores do Programa de Extensão Popular Tecelendo da UFRB.

${ }^{2}$ Pedagoga pela Faculdade Olga Mettig. Especialista em Educação de Jovens e Adultos na Universidade do Estado da Bahia- UNEB. Especialização em Educação Integral pela Universidade Federal da Bahia (UFBA).

${ }^{3}$ Professor de filosofia da educação e filosofia da ancestralidade da Universidade Federal do Recôncavo da Bahia (UFRB), Centro de Formação de Professores, Amargosa-BA. Tem a seguinte formação: Pós-doutor em Educação Universidade Federal da Paraíba/FACED (2012) Doutor em Educação (2008) Universidade Federal do Ceará/FACED. Mestre em Educação (2004) pela Universidade Federal da Bahia/FACED. Especialista em Estética, Semiótica, Cultura e Educação (2001): Universidade Federal da Bahia/FACED. Bacharel em Filosofia (1999): Universidade Católica do Salvador
} 


\section{INTRODUÇÃO}

É inquestionável que a nossa sociedade brasileira é multirracial e pluriétnica. Sendo assim, é fundamental pesquisas e discussões que se debruçam sobre as mais variadas questões que perpassam à nossa população, se assim quisermos ter equidade. Numa sociedade em que 53,6\% é negra (pretos e pardos) segundo dados do IBGE em 2014, é importante que possamos reconhecer a nossa história, a nossa origem, a nossa luta e para isso políticas públicas que garanta também as políticas afirmativas. Neste sentido, a lei 10.639/03 que modifica o artigo $26^{\mathrm{a}}$ da Lei de Diretrizes e Bases da Educação Nacional (LDBEN), vem ressignificar a história do negro no Brasil, como estratégia para mudança do autoconceito, crítica ao eurocentrismo e a violência histórica cometida com o povo negro.

O presente artigo tem como objetivo analisar as contribuições da oficina de capoeira desenvolvida numa Escola Municipal de Salvador-Ba, inserida nas atividades do programa Mais Educação. O Programa Mais Educação, foi instituído pela Portaria Interministerial $n^{\circ} 17 / 2007$ e regulamentado pelo Decreto 7.083/10, constitui-se como estratégia do Ministério da Educação para induzir a ampliação da jornada escolar e a organização curricular na perspectiva da Educação Integral.

$\mathrm{O}$ estudo em questão centrou-se nos seguintes questionamentos: quais as contribuições da oficina de capoeira no processo de aprendizagem de estudantes de uma Escola Municipal da cidade de Salvador-Ba? Como os diferentes sujeitos envolvidos na referida oficina percebem seus processos e podem apontar perspectivas para $\mathrm{o}$ desenvolvimento de práxis crítica?

É preciso destacar, que na condição de educadores e de seres humanos em processo de humanização, não podemos fugir de nossa vocação ontológica de intervenção no mundo (FREIRE, 2014). Se rejeitamos esta ação, então nos colocamos em movimento afastado da dimensão ética e do compromisso de responsabilidade com o mundo e o outro. A partir da consciência que é constituída de presença no mundo é que não podemos fugir de nossa vocação. Somos permeados por todas as situações alheias e adversas, mas não somos um ser que se adapta ao alheio, nos inserimos nele, nos refazemos, criamos e recriamos. Assim, agimos como sujeitos da história e não apenas mero objetos formatados, passivos, ou seja, somos sujeitos da ação e da luta.

De acordo com Paulo Freire, (2007, p. 15): “(...) o homem só se expressa convenientemente quando colabora com todos na construção do mundo comum - só se 
humaniza no processo dialógico de humanização do mundo". Processo este que perpassa o sujeito desde seu contexto à apropriação de sua historicidade, de suas lutas e escolhas. Perpassando pela conscientização de perceber o mundo não mais como simples espetáculo passivo e sim como momento de convocação a transformá-lo, criálo e apropriar-se de sua história. É nestes movimentos que buscamos refletir sobre a experiência com a prática da capoeira no chão de nossas escolas.

Entendemos a sociedade na qual estamos inseridos como propiciadora de atitude e valores. Uma das tarefas importante da prática educativa crítica é a criação de condições em que os educandos ensaiam uns com os outros a experiência de assumirse. Pois conhecer é praticar. É conhecendo sua realidade e repensando sobre seu contexto que através da atitude crítica e problematizadora nos assumimos como seres históricos, sociais, críticos e transformadores.

O percurso textual deste artigo está estruturado na seguinte lógica: inicialmente apresentamos o método e os procedimentos que nos apoiamos nesta pesquisa; seguindo a exposição, tecemos um diálogo com questões que perpassam a educação, principalmente questões pertinentes a lei 10.639/03 modificada pela lei 11.645/08 (História da cultura Afro-Brasileira, Africana e Indígena) a partir de uma experiência com o Programa Mais Educação do Ministério da Educação (MEC); partimos do percurso histórica referente a origem, o significado e as possibilidades com a prática da capoeira como manifestação da cultura e produção de saberes-aprendizagens significativas, bem como, a necessidade de elaborar práticas pedagógicas como o ensino desta arte-jogo-prática no processo de construção da identidade de crianças e de valorização da cultura Afro-Brasileira; Detalhamos mais adiante como se estruturou o Programa Mais Educação na escola foco de nossa investigação e o contexto social e cultural onde a mesma se encontra localizada; nos achados da pesquisa, apresentamos as falas dos sujeitos entrevistados relacionando os teóricos que elucidam as questões que foram evidenciadas em nossa problematização; por fim, apresentamos as conclusões.

\section{PERCURSOS METODOLÓGICOS}

Do ponto de vista epistemológico a metodologia expressa a concepção da relação sujeito-objeto do pesquisador; a visão de mundo que perpassa objetivo da de pesquisa, o grau de relação entre o fenômeno estudado e a totalidade concreta imprime 
a direção que o pesquisador toma em relação ao problema investigado. Por isso, ao fazer ciência assumimos uma postura no mundo de não neutralidade (PINTO, 1979). Assim, tomamos como ponto de partida teórico-metodológico a concepção de Pimenta (2014, p.76) ao expressar que a metodologia traz embutida uma concepção de investigação que pode contribuir para a construção de um conhecimento educacional crítico, transformador e emancipatório

Com o objetivo de analisar as contribuições da capoeira no desenvolvimento dos educandos, adotamos a pesquisa participante tendo em vista buscar conhecer os resultados no contexto do tema pesquisado levando em consideração o envolvimento dos pesquisadores no contexto empírico da pesquisa. $\mathrm{O}$ instrumento utilizado foi a entrevista semiestruturada com o objetivo de conhecer as percepções dos sujeitos envolvidos na oficina de capoeira em uma escola da rede pública de ensino da cidade de Salvador-Ba. Conforme Lakatos e Marconi (1999) "a entrevista é o encontro entre duas pessoas, a fim de que uma obtenha informações a respeito de determinado assunto, mediante uma conversação de natureza profissional (p. 94)".

As entrevistas foram realizadas no segundo semestre de 2015, durante os meses de outubro, novembro e dezembro, onde foram gravadas e transcritas na íntegra para uma melhor análise das informações. Os sujeitos entrevistados foram: a coordenadora do Programa Mais Educação devido seu acompanhamento pedagógico na oficina, um aluno em distorção idade-série e o Mestre de Capoeira (oficineiro).

Estabelecemos um vínculo com a escola devido a um dos pesquisadores ser professor na referida instituição. Esta aproximação inicial facilitou a aproximação com os sujeitos da pesquisa. Realizamos um contato prévio presencial com a coordenadora, do Programa Mais Educação, com o Mestre de Capoeira (ministrante da oficina) e com o estudante afim de combinamos os encontros e as regras de realização das entrevistas de forma que pudéssemos utilizar e publicar os dados resultantes de nossos estudos.

Todos os encontros com os sujeitos entrevistados foram feitos na Escola pública os entrevistados possui vínculo e onde acontece a oficina foco de nossa pesquisa. Ao realizar as entrevistas na escola, buscamos observar as situações que emergiam no momento da realização da entrevista.

Dado a natureza do problema desta investigação buscamos aportes em uma abordagem qualitativa, bibliográfica (ANDRÉ, LÜDKE, 1986; MINAYO, 2007; TRIVIÑOS, 2013). Compreendemos que a pesquisa bibliográfica se utiliza das contribuições dos/as diversos/as autores/as sobre um determinado assunto ajudando a 
mapear as perguntas outrora já elaboradas naquela área de conhecimento, permitindo identificar o que mais tem se enfatizado e o que tem sido pouco trabalhado.

\section{A CAPOEIRA E SEUS PERCURSOS HISTÓRICOS}

Segundo o pesquisador Hélio Campos (2001) há várias hipóteses para a origem da capoeira, entretanto há duas fortes correntes: uma afirma que a Capoeira teria vindo para o Brasil trazida pelos povos africanos, a outra diz que é uma invenção dos povos africanos no Brasil. Segundo Waldeloir Rêgo (1968) em seu livro Capoeira Angola:

[...] tudo nos leva a crer que seja a Capoeira uma invenção dos africanos no Brasil, desenvolvida por seus descendentes afro-brasileiros, tendo em vista uma série de fatores colhidos em documentos escritos e sobretudo no convívio e diálogos constantes com os capoeiristas atuais e antigos que ainda vivem na Bahia (REGO, 1968, p. 31)

A capoeira, manifestação esportiva cultural, é uma prática cultural popular de jogo, ginga, golpes e dança em roda, animados por instrumentos musicais como o pandeiro, o atabaque e o berimbau. Por meio da capoeira, é possível revisitar a atualização de antigos dilemas raciais e, ainda, perceber os vínculos entre manifestações populares e eruditas, ou entre a música na capoeira e a poesia na vida real. A capoeira está centrada em torno da honra coletiva e da estratégia corporal de cada praticante da modalidade (capoeirista). Há esforço constante, trabalho e cálculo, intimamente vinculados ao combate e ao cuidado com o convívio grupal.

Vivências práticas com os fundamentos da capoeira não devem se restringir à pura execução biomecânica de movimentos e golpes, mas acompanhadas de discussões sobre os rituais, as diferentes nomenclaturas, a etimologia, a aplicação, as possibilidades de sistematização, os significados e as representações dos golpes em um arsenal cultural.

Entendo a capoeira como símbolo da cultura é preciso entendermos que sentido de cultura estamos defendendo. A palavra cultura na sua origem etimológica é oriunda do verbo latino colere significando o cultivo, o cuidado. Inicialmente podemos pensar a cultura como um modo de vida, de pensamento ou como campo próprio instituído pela ação humana referente a todos os aspectos da vida social. Etimologicamente a palavra cultura dimensiona para a natureza, a "lavoura", "cultivo agrícola" que entrelaça um movimento tanto de um crescimento espontâneo como movimento regulado, elaborado. 
Segundo Chauí (2008) ligada ao cultivo e ao cuidado com a terra, nos dá a noção de agricultura, já o cuidado com as crianças, denomina-se puericultura. Com os deuses e o sagrado, surge o "culto" que no latim, refere-se o termo cultus, compreendendo tanto o sentido religioso quanto aos cuidados com os pertences. Como cultivo, a cultura era concebida como uma ação que conduziria a plena realização das potencialidades de alguma coisa ou de alguém.

A cultura não é estática pois é sempre uma tensão entre aquilo que é racional e espontâneo. Não sendo determinada e fixa, muito menos deliberadamente modificada, ela implica aquilo que a natureza realiza em nós, a saber, as ações que realizamos na própria natureza. A cultura é um movimento oriundo de seu próprio processo vital. Neste sentido, é necessário compreendermos que sobre o conceito de cultura, na raiz de toda significação, há elementos significativos que são movidos pela junção de significado e de poder, por sua vez, só podem ser identificados a partir da própria cultura, do seu contexto social.

A Capoeira além de ser uma expressão cultural ancestral, se caracteriza também como uma atividade física e que pode contribuir para a formação integral do estudante. Sua riqueza consiste em praticá-la como: luta, dança, arte, resistência, manifestação popular, esporte, lazer, filosofia de vida etc.. Infinitas perspectivas e práticas de capoeira que podem ser desenvolvidas e trabalhadas na instituição escolar.

A capoeira tem o potencial de nos integrar e tencionar a compreender a cultura, incentivar a criatividade, desenvolver e aperfeiçoar as qualidades psicomotoras, proporciona mudanças comportamentais, tais como, o respeito, a integração, o diálogo e a solidariedade (REGO, 1968). A valorização da capoeira enquanto manifestação cultural, busca trabalhar com a sua historicidade e a expressividade de um povo que luta e se recria para sobreviver contra as opressões e preconceitos. Em cada movimento da dança, do jogo, a capoeira está inserida no movimento cultural que é político e emancipador.

A prática e o ensino da capoeira não exigem espaço específico, podendo ser realizada em um salão, pátio, ao ar livre, debaixo de uma árvore, desde que observadas medidas de segurança para seus participantes. As vestimentas, os praticantes (capoeiristas) utilizam camiseta e calça de helanca, ambas brancas, que possibilita a execução confortável dos movimentos pela elasticidade e característica do material. Como sistema de graduações, a capoeira adota o sistema de cordas de algodão coloridas 
amarradas na cintura que indicam o estágio em que o praticante se encontra. A ordem, a quantidade e as cores das graduações variam de acordo com cada escola/grupo e etnia.

\section{A PRÁTICA DA CAPOEIRA COMO ATIVIDADE EDUCADORA}

Dentre as manifestações culturais legadas pelos escravos africanos no Brasil, sejam elas lúdicas, religiosas, alimentares, ritualistas ou laborais, a capoeira é uma das mais representativas ao lado do Candomblé, e ambos têm sofrido a influência dos impactos negativos causados pelos interesses capitalistas da indústria cultural. Uma educação plural, responsável com a sociedade brasileira precisa revisitar a sua ancestralidade e experiências vividas ao longo dos anos, fortemente marcados por condições de vida desumanas e pelas diversas formas de resistência.

A oficina de capoeira proporciona um olhar sobre essa resistência na medida em que promove a integração dos alunos e atende aos anseios da Lei 10.639 promulgada em 2003 com o objetivo de reparar um erro histórico frente à história e as práticas culturais da comunidade negra africana e brasileira.

A Lei 10.639/2003 e a Resolução CNE/CP/2004 é um dos marcos importantes para a efetivação de ações que possam criar a reparação das injustiças que acabam resultando no racismo e de diversas formas de discriminação. O Conselho Nacional de Educação institui as Diretrizes Curriculares para a Educação das Relações ÉtnicoRaciais e o Ensino de História e Cultura Afro-Brasileira e Africana a serem executadas obrigatoriamente pelos estabelecimentos de ensino de diferentes níveis e modalidades, promovendo a formação dos docentes e sob sua responsabilidade orientar e supervisionar o cumprimento das Diretrizes.

A aplicação da lei é de responsabilidade de todos na comunidade escolar, o desafio é superar preconceitos e estigmas excludentes que pairam sobre a população negra no Brasil. Nessa perspectiva de mudança, pesquisas e leituras diversas sobre o tema, é primordial para a escuta, a integração, a ruptura de barreiras, a abertura ao diálogo, para a vida e para compreender e respeitar o outro.

Percebemos que os modelos convencionais estabelecidos pelo sistema neoliberal, excludente e desigual cria situações opressoras há tanto arraigados em nossa sociedade elitista e excludente. As massas menos favorecidas durante muito tempo em nossa sociedade brasileira foram estimuladas e formadas a aceitarem as condições que os impossibilitavam de pensar e agir por mudanças. Os excluídos são colocados a 
aceitarem pela opressão e ideologia dominante a condição de dominados, sem opiniões e descrentes de si mesmos. Não percebem sua relação dialógica com o mundo que o circunda, pois não se veem como agentes participantes e incluídos na historicidade.

Segundo Freire (1997) homens e mulheres, ao longo da sua historicidade, vítimas de todo tipo de exclusão e autoritarismo, ao fazerem a leitura de mundo e elaboradores da cultura vão percebendo-se como seres inconclusos, limitados, condicionados, históricos e da ação. Percebendo, sobretudo, também, que a pura percepção do inconcluso, da limitação, da possibilidade, não basta. É preciso juntar a ela a luta política pela transformação do mundo. A libertação dos indivíduos só ganha profunda significação quando se alcança a transformação da sociedade (FREIRE, 1997, p. 53).

A capoeira como prática pedagógica busca possibilitar uma reflexão sobre todos os envolvidos no ambiente escolar onde se aprende a conviver com as diferentes formas de agir, pensar e se relacionar, auxilia na promoção da igualdade, busca desenvolver a autonomia, quebra de paradigmas e mitos criados pela sociedade que em muitos momentos reforça imagens e ações discriminatórias.

No contexto escolar busca-se valores como respeito, afeto, sensibilidade, amor ao próximo, sem discriminação de cor, credo, sexo ou classe social. A escola, como espaço multicultural, necessita atentar para sua responsabilidade política e social, a fim de estimularem indivíduos políticos e críticos dos seus contextos nas realidades em que estão inseridos.

\section{O PROGRAMA MAIS EDUCAÇÃO NA ESCOLA MUNICIPAL DO CALABAR ${ }^{4}$}

A Escola Municipal do Calabar foi fundada por um grupo de mulheres Rotarianas $^{5}$. As esposas dos associados ao Rotary Club necessitavam de espaço para desenvolver atividades comunitárias, sendo assim, conseguiram pela Prefeitura Municipal de Salvador-Ba um terreno situado do Jardim Apipema/Ondina para construção de uma Casa-sede: Casa da Amizade e em contrapartida o referido Órgão exigiu que as senhoras dessem retorno à sociedade. Resolveram então construir duas

\footnotetext{
${ }^{4}$ Optamos por caracterizar a escola com o nome do Bairro onde está inserida. Atentos ao princípio ético de pesquisa preservamos seu nome verdadeiro.

${ }^{5}$ O Rotary se caracteriza como uma organização composta de profissionais e líderes de negócios, que prestam serviços humanitários, Rotary Club é definido como um clube de serviços à comunidade local sem fins lucrativos, filantrópico e social.
} 
salas de aula e posteriormente mais duas que foram inauguradas no ano de 1985. A escola então começou seu funcionamento mantida pela Prefeitura.

Atualmente a escola atende a 250 alunos, sendo que a maioria é oriunda da comunidade do Calabar, e das comunidades da Roça da Sabina (Ondina), do Amazonas e do Gavazza, ambas na Barra. Filhos de trabalhadores domésticos, desempregados e subempregados, uma parte significativa depende do Programa Bolsa Família para sobreviver. Possui 38 funcionários, alguns desses moram próximos à Unidade que funciona em dois turnos, turmas de Educação Infantil (Grupo 4 e Grupo 5) e do $1^{\circ}$ ao $5^{\circ}$ ano do Ensino Fundamental.

A adesão da Escola Municipal do Calabar ao Programa Mais Educação do Ministério da Educação e Cultura (MEC), se deu no ano de 2012. O intuito é melhorar o desenvolvimento da instituição no que diz respeito ao Índice de Desenvolvimento da Educação Básica (IDEB), atender crianças em situação de vulnerabilidade social e com distorção idade-série.

O Programa Mais Educação em suas ações visa diminuir as desigualdades educacionais valorizando a diversidade cultural. O programa envolve a participação de vários profisssionais da educação e de outras áreas, as famílias e diferentes atores sociais sob a coordenação da escola e professores. Como proposta de Educação Integral, a Portaria Interministerial $n^{\circ}$ 17/2007 reafirma o compromisso da sociedade e da família no dever de educar, conforme determina a Constituição Federal:

\footnotetext{
A educação, direito de todos e dever do Estado e da família, será promovida e incentivada com a colaboração da sociedade, visando ao pleno desenvolvimento da pessoa, seu preparo para o exercício da cidadania e sua qualificação para o trabalho. (Art. 205, BRASIL)
}

O Programa Mais Educação atende em princípio escolas de baixo IDEB situadas em capitais, regiões metropolitanas e grandes cidades marcadas por situação de vulnerabilidade social que necessitam urgentemente de políticas públicas e educacional. Neste sentido, o programa define alguns critérios para definição do público a ser atendido: estudantes que estão em situação de risco, vulnerabilidade social e sem assistência; em defasagem série/idade; estudantes de séries onde são detectados índices de repetência; estudantes do $4^{\circ}$ e $5^{\circ}$ anos nas quais há uma maior evasão na transição para a $2^{\text {a }}$ fase $\left(\right.$ do $6^{\circ}$ ao $9^{\circ}$ ano).

Cada escola possui seu projeto político pedagógico e em diálogo com a comunidade define quais alunos participarão das atividades seguindo os critérios 
citados. Em relação às atividades, as mesmas são organizadas nos seguintes macrocampos: Acompanhamento Pedagógico; Alfabetização; Educação Ambiental; Esporte e Lazer; Direitos Humanos em Educação; Cultura e Artes; Cultura Digital; Promoção da Saúde; Comunicação e Uso de Mídias; Investigação no Campo das Ciências da Natureza; Educação Econômica.

De acordo com os macrocampos, a Escola Municipal (foco da pesquisa) organiza suas atividades da seguinte forma: 1. Acompanhamento Pedagógico (Matemática e Letramento); 2. Esporte e lazer - (Xadrez tradicional); 3. Cultura e Artes- (Leitura, Dança, Capoeira). Atentamos aqui para a atividade foco de nossa investigação. A Capoeira, segundo Campos (2001, p.23), "é uma excelente atividade física e de uma riqueza sem precedentes para ajudar na formação integral do aluno". Existem várias formas de praticá-la e cada pessoa pode escolher a forma que mais se identifica:

Capoeira luta- representa a luta e resistência através dos tempos e como instrumento de defesa pessoal genuinamente brasileiro. $\mathrm{O}$ objetivo dessa modalidade é combate e defesa.

Capoeira dança e arte- A arte presente através da música, canto, instrumento, expressão corporal, criatividade de movimentos. Na dança, as aulas deverão aproveitar os movimentos da capoeira, desenvolver a flexibilidade, equilíbrio, agilidade e coordenação.

Capoeira folclore- expressão popular que faz parte da cultura brasileira que deve ser preservada.

Capoeira esporte- como modalidade desportiva e institucionalizada em 1972 pelo Conselho Nacional de Desportos, deverá ter um enfoque especial para competições.

Capoeira educação- importante para formação integral, desenvolvendo o físico, o caráter e a personalidade, influenciando nas mudanças de comportamento. Propicia ainda um auto-conhecimento e uma análise das potencialidades e limites de cada aluno. Na educação especial é importante para o desenvolvimento de alunos com necessidades especiais.

Capoeira como lazer- prática não formal através de "rodas " espontâneas.

Capoeira filosofia da vida- muitos adeptos que se engajam criando uma filosofia de vida, tendo a capoeira como símbolo (CAMPOS, 2001, p. 23).

A oficina de Capoeira foi implantada na Escola Municipal do Calabar através do Programa Mais Educação, entrelaçando as modalidades de Capoeira dança, arte e Educação de forma que atendesse a todos os alunos de forma inclusiva. No contexto sócio-cultural da comunidade, na qual a referida escola está inserida, no bairro do 
Calabar, sua ocupação teve início entre os anos de 1940 a $1950^{6}$. Segundo o historiador, o local era um quilombo, formado por escravos de origem nigeriana.

No norte da Nigéria existia (e ainda existe) uma área chamada de Kalabari e essa seria a origem do nome da comunidade que começara a ser formada - o Quilombo dos kalabari. Foi nas décadas de 1950 e 1960 que o Calabar passou a obter os traços que possui hoje. Quando a comunidade passou a contar com uma população muito maior, vinda de levas de famílias expulsas de diversos lugares da cidade e de famílias do interior do estado da Bahia, motivadas pelo êxodo rural a se estabelecer na capital baiana em busca de melhores condições de vida e novas oportunidades de trabalho. No entorno do Calabar ficam localizados o Cemitério do Campo Santo na Federação e o Alto das Pombas, de um lado a Av. Centenário, Posto de Gasolina e do outro lado alguns prédios em Ondina e a Faculdade de Filosofia da Universidade Federal da Bahia.

Uma população que sofre com os problemas gerados pela falta de recursos econômicos, (na maioria das vezes vive em situação de miséria), levando-a a conviver com vários problemas tais como: violência, dependência de drogas altas taxas de gravidez na adolescência, baixa escolaridade das famílias e etc. Todo espaço livre é utilizado para construção de casas. Nesse cenário, pode-se ver um mundo em que se evidenciam problemas que envolvem as inter-relações e interdependência dos diversos elementos de constituição e manutenção da vida.

A adesão da Escola Municipal ao Programa Mais Educação ocorreu no ano de 2012 visando melhorar o Índice de Desenvolvimento da Educação Básica (IDEB). O programa visa atender crianças em situação de vulnerabilidade social e com distorção idade-série.

\section{A OFICINA DE CAPOEIRA NO CHÃO DA ESCOLA: O QUE DIZEM OS SUJEITOS DA PESQUISA?}

Para a realização da pesquisa buscamos fazer uma delimitação dos sujeitos que participariam desse estudo. Tal delimitação pautou-se em alguns pré-requisitos, a saber: I.O Mestre de Capoeira (oficineiro) devido ao envolvimento com os alunos e a

\footnotetext{
${ }^{6}$ Existem duas versões sobre seu aparecimento. Uma diz que no local havia uma antiga fazenda, chamada de Fazenda São Gonçalo, e nela algumas pessoas passaram a construir suas moradias, uma versão muito comum a outros bairros de Salvador. A outra versão, contada pelo historiador Cid Teixeira e bastante original, diz que o local teve início no período escravista brasileiro, que só teve fim em 1888. Desta forma, mesmo sem uma data precisa, é possível reconhecer por meio dessa versão que o local tem um passado bem remoto e historicamente importante
} 
demanda de sua oficina ser uma das mais procuradas na referida na escola pesquisada; II.Um aluno pelo seu desempenho e histórico de distorção série-idade e por ter se destacado pela escola e pelo mestre de capoeira no desenvolvimento das atividades e práticas solicitadas; III.A coordenadora do Programa Mais Educação pelo acompanhamento pedagógico na oficina.

A oficina de capoeira é uma das atividades mais procurada pelas crianças na Escola do Calabar, isso ficou evidente na fala dos entrevistados e nas inscrições da oficina. O oficineiro, que é mestre em capoeira, exerce a prática há 33 anos e atua há 25 anos em projetos de diferentes escolas da cidade de salvador. Desde de 2012 atua como oficineiro do Programa Mais Educação. As entrevistas foram realizadas na própria escola campus da pesquisa, em uma sala de aula, no horário do intervalo do recreio escolar, portanto, foi permeada por gritos infantis, algazarra e brincadeiras.

Percebemos na prática pedagógica do mestre a identificação de muitos momentos com os modos da cultura popular, onde a oralidade se sobrepõe a palavra escrita, e onde os saberes e conhecimentos dos mais velhos têm muita importância para o seu fazer. O oficineiro descreve seu trabalho como:

[...] uma profissão que gosto muito de trabalhar com crianças, mas tem que ter paciência e dedicação senão não consegue desempenhar sua profissão, é como uma escola, se a professora não tiver o dom até os alunos saturam dela (MESTRE CAPOEIRISTA, 2015).

O mestre explica o que entende por “dom” e porque é necessário:

[...] por todos os sentidos, dom em qualquer arte, para fazer aquilo que gosta. Se fizer o que não gosta não desenvolve bem seu trabalho (MESTRE CAPOEIRISTA, 2015)

O oficineiro na sua prática descreve a sua profissão/arte como algo que aparentemente é inato e que exige um sentimento de amorosidade, ao mesmo tempo que parece transparecer que o "dom" exige de um lado algum conhecimento da prática, da paciência, de como lidar com as situações diversas. Acreditamos que a docência exige além do esforço pessoal, estudos, planejamento e dedicação (amorosidade), formação inicial e continuada para o educador no exercício de sua docência. O processo de formação que requer tempo, dedicação e condições para o profissional qualificar-se no seu ofício. 
$\mathrm{Na}$ entrevista, o mestre de capoeira destaca o tempo todo a importância da capoeira desde ressaltando a necessidade de ser trabalhada desde a Educação Infantil até a fase adulta. É importante destacar que, o trabalho realizado pelo mestre, na condição de oficineiro com a prática da capoeira, expressa um símbolo da cultura africana, de resistência e principalmente de resgate da história do povo negro.

O trabalho com a cultura afro-brasileira nos ajuda a revelar as conquistas, lutas e vitórias de uma história invisibilizadas e negada constantemente por práticas pedagógicas desvinculada de uma relação de um currículo contextualizado. Segundo Nascimento $(1992, \mathrm{p} 1)$ "resgatar a nossa memória significa resgatar a nós mesmos da armadilha da negação e do esquecimento, significa estarmos reafirmando a nossa presença ativa na história pan-africana e na realidade universal dos seres humanos".

Ao expressar seu olhar visionário de capoeirista e de educador, durante anos de prática nesta arte, o mestre capoeirista deixa transparecer um certo desapontamento para alguns alunos que ao tornarem-se adultos esquecem as rodas de capoeira, os aprendizados e as relações de amizade, respeito e companheirismo. Neste sentido, a fala do mestre apresenta elementos pertinentes que ao nosso olhar são importante para serem analisadas, a saber a necessidade da disciplina, entendida como comprometimento, e de particularidades que perpassam a práxis de diversos educadores em sua função docente frente a contextos permeados de contradições. Segundo o mestre:

[...] Tem alunos que seguem a cartilha certa, os ensinamentos, acho que a maioria acompanha a roda, respeitando a disciplina, outros quando estão engatinhando na capoeira obedecem, quando ficam adultos não querem respeitar acham que não precisam do conselho do mestre, não aceitam a disciplina. Eu mesmo tenho 49 anos quando o mestre reclama comigo, não é por minha causa mas por causa dos alunos, eu escuto, depois converso com ele e fica tudo bem, tem que ter disciplina e ouvir o mestre. O educador de capoeira é como um psicólogo, age até como pai para muitas crianças, ouve, dá conselhos pois os pais saem para trabalhar e eles ficam com as tias, avós, nas creches, então o mestre é uma figura importante na vida deles. É gratificante trabalhar com crianças mais do que com adultos, elas te encontram, te abraçam, é muito bom (MESTRE CAPOEIRISTA, 2015).

A fala do mestre capoeirista expressa a realidade que assola os nossos bancos escolares, entre angústias e demandas de grupos que vivências diversas formas violentas de negação e exclusão. Percebemos que a maioria das famílias negras em sua realidade são transpassadas por infinitas dificuldades de diferentes ordens, como por 
exemplo, o acompanhamento e apoio das crianças em seu desenvolvimento emocional e intelectual. Segundo Silva Monteiro (2000, p. 81):

[...] como poderá alguém desabrochar seu corpo que é físico, que é inteligente, percepção, sentimento, emoção, alegria e espontaneidade, sendo ele negro num mundo em que o feio, o negativo, o errado, o mau é qualidade de negro? Refazendo sua história de dor e negação.

Compreendemos que as consequências dessa trágica história mal contada que criam o imaginário e o comportamento dessas crianças tem como resultado uma usurpação de si mesmas, gerando prejuízos e preconceitos a construção da identidade pessoal, racial, gênero e política, vilipendiando uma aprendizagem significativa que possibilite a autoestima e a apropriação de sua cultura.

O estudante Besourinho ${ }^{7}$, uma criança de 10 anos de idade, negra e de família pobre, questionado sobre seu envolvimento na oficina de capoeira, nos responde:

[...]quando fui a primeira vez na roda, fiquei muito feliz, aí eu não sabia jogar direito os mestres ensinavam como fazer os movimentos. Ensinar as pessoas que não é para fazer a mesma que a gente fazia como ficar na rua, deve ficar dentro de casa ou fazer capoeira, jogar bola, fazer um esporte, não ficar na rua, ficar longe do mundo das drogas, aprender a respeitar as pessoas (ESTUDANTE BESOURINHO, 2015)

E continua:

[...] é importante passar o que aprendi, senão não vai pra frente, tem que ajudar os mestres, os professores, incentivar a ser como eu que vim para a capoeira, ajudar aos professores, os mestres a tirar os meninos da rua convidando para fazer capoeira. Uns vêm outros não (ESTUDANTE BESOURINHO, 2015).

Nesse aspecto, o estudante ressalta a dinâmica do estar em capoeira em roda como espaço de integração e aprendizado. A roda é um elemento circular onde todos se olham e onde o discurso circula na horizontalidade e onde os gestos e "golpes" são observados e apreendidos no movimento corporal. A fala do estudante, no seu envolvimento com a prática da capoeira, aponta para a necessidade de pensarmos a autoestima como valor pessoal.

\footnotetext{
${ }^{7}$ Caracterizamos pelo nome de Besourinho devido o estudante se identificar com o filme brasileiro que conta a vida de Besouro Mangangá, um capoeirista brasileiro da década de 1920. A entrevista foi realizada no pátio da escola durante o intervalo de suas atividades.
} 
A importância de estar integrado e a capacidade de lidar com os desafios do cotidiano, possibilita ao estudante processos de respeito e defesa de interesses comuns e coletivos podendo assim, estimular a integração e envolvimento. Por outro lado, segundo Campos Junior (1999), a autoestima baixa, em relação a população negra, refere-se também entre outros fatores a um sentimento de inadequação à vida como pessoa frente a uma cultura estigmatizada e inferiorizada:

[...] acredita-se que o negro vai desenvolver em si mesmo o sentimento de autoestima. Esse processo consiste em ações que promovam o resgate de cultura e história do negro evidenciando seus heróis, eliminando definitivamente os estereótipos, preconceitos dos livros didáticos que evidenciam o negro sempre de forma inferior (CAMPOS JUNIOR, 1999, p. 73)

Isto nos leva a pensar em um trabalho respaldado na Lei 10.639/03 e 11. 645/08 (História da Cultura Afrodescendente e Indígena) como a consciência racial e identitário contra o silêncio, invisibilidades e denúncias sobre o direito dos povos negros e indígenas. Concordamos com Santos (2013) que estas leis expressam simbolicamente uma necessidade correção do Estado brasileiro pelo débito histórico com políticas públicas voltadas para a população negra e indígena. Segundo Santos (2013) e Munanga (1994) é importante frisar que a discriminação racial não perpassa apenas crianças negras, por isso, a necessidade de trabalhar no ambiente escolar contra ideologias que reforçam qualquer tipo de discriminação. Na condição de professores entendemos ser necessário o preparo e formação para desafios com a convivência, a diversidade que cotidianamente envolve a vida profissional. É preciso rompermos os discursos eurocêntricos, o mito da "democracia racial" e garantirmos, como aponta Santos (2001, p. 9), "situações de diálogo, de questionamentos e favorecer uma vivência que permita todos da comunidade escolar garantir e promover o conhecimento de si mesmo, no encontro com o diferente".

Aprender capoeira, por exemplo, é manter vivo o jeito de ser do povo, é trabalhar a identidade cultural e a diversidade. O aprendiz envolve-se como um todo tirando lições extremamente ricas para a vida. Mesmo quando cada educando executa movimentos individualmente, seguindo os passos orientados pelo mestre, a aprendizagem se processa coletivamente, na medida que todos estão atentos, sentados na roda, observam e acompanham os movimentos dos colegas que se encontram no centro da roda. 
No decorrer das oficinas, o aluno besourinho consegue expressar-se, se movimenta com mais liberdade, o que não é possível durante as atividades de sala de aula. Trata-se de um jogo coletivo que traz benefícios para o corpo e mente, como explica nossa terceira entrevistada, a coordenadora do Programa Mais Educação, quando entrevistada sobre sua percepção referente a oficina e quais os resultados ela consegue identificar nesta experiência, ressalta que:

\footnotetext{
[...] são trabalhados conteúdos relacionados ao histórico da capoeira, saberes trazidos pelos alunos sendo que através da interação do grupo é possível os alunos aprenderem a conhecer ou se apropriar da sua cultura, construção da identidade, desenvolve a concentração, atenção, respeito, desenvolve relação. Ainda aprimora a coordenação motora geral, a lateralidade, a organização espaço-temporal (COORDENADORA, 2015).
}

Percebe-se que a coordenadora compreende a oficina de capoeira estabelecendo um laço com o Projeto Político Pedagógico da escola, possibilitando trabalhar desde a linguagem oral e escrita, a corporal, artística, valorizando a pluralidade cultural. Nesse sentido, acompanha os oficineiros na sua prática voluntária, observando os alunos que participam, aqueles que têm dificuldades em trabalhar em grupo, até que se adaptem, com problemas cognitivos, com necessidades especiais buscando possibilidades de inserir a todos neste processo.

É importante destacar que coordenadora pedagógica tem formação em Magistério, licenciatura em Pedagogia e Especialização em Psicopedagogia. Sua função é acompanhar os oficineiros e situá-los a respeito do Projeto Político Pedagógico da escola, providenciar fichas e formulários para pagamento dos monitores/oficineiros. Manter contato constante com a Secretaria Municipal de Educação sobre a viabilidade do Programa Mais Educação e as determinações do Ministério da Educação-MEC. Tem a responsabilidade também de manter informada a gestão da escola sobre a dinâmica do Programa, semanalmente. Providenciar espaços físicos para a realização das oficinas; pesquisar e acompanhar as situações didáticas. Disponibilizar os materiais didáticos e recursos materiais para cada oficina.

Ao chegar à escola nomeada para coordenar o Programa, a coordenadora afirmou que o mesmo já acontecia de forma precária, em espaço físico inadequado, como observa: 
acostumando com a dinâmica do Programa Mais Educação, ainda não era possível o diálogo entre o que era trabalhado em sala e no Programa Mais Educação (COORDENADORA, 2015).

$\mathrm{Na}$ fala da entrevistada, fica evidente algumas fragilidades em relação a execução do Programa Mais Educação. O referido programa foi inserido e implementado sem que houvesse formação para os monitores e o corpo docente para trabalharem de forma contextualizada e sem conhecimento aprofundado da sua funcionalidade, bem como de seus objetivos. Isso foi sendo superado aos poucos pela gestão da escola com o estudo do material disponibilizado pelo MEC e com a chegada da coordenadora que se deparava então com inúmeras dificuldades.

Na concepção defendida por Freire (2007) o ato de ensinar se articula com o ato de aprender num processo vivido coletivamente por aprendentes historicamente desde tempos remotos:

Ensinar inexiste sem aprender e vice-versa e foi aprendendo socialmente que, historicamente, mulheres e homens descobriram que era possível ensinar. Foi assim, socialmente aprendendo, que ao longo dos tempos mulheres e homens perceberam que era possível- depois, preciso- trabalhar maneiras, caminhos, métodos de ensinar. Aprender precedeu ensinar ou, em outras palavras, ensinar se diluía na experiência realmente fundante de aprender (FREIRE, 2007, p. 23-2).

Faz-se necessário a problematização da relação educador/educando e a atitude formativa provocada por tal relação. É preciso que desde o início tenhamos claro que quem ensina está a 'formar' alguém e ao mesmo tempo forma-se e reforma-se. A atitude do educador é um movimento de construção em uma relação "recíproca" que, quem exerce essa função não é o tempo todo sujeito da ação de ensinar e o educando, mesmo estando em uma relação de formação, também ensina. $\mathrm{O}$ educando não está apenas em uma relação de objeto e de atitude passiva perante o saber, neste sentido tem uma relação com o conhecimento de ressignificação e uma função ativa de produção do mesmo. O ensinar é visto não mais como transferimento de conhecimentos, mas como possibilidade que cria diversas perspectivas de construções de saber.

Uma das tarefas importante da prática educativa crítica é a criação de condições em que os educandos ensaiam uns com os outros a experiência de assumir-se e é este o movimento que a capoeira possibilita a ressignificação de si. Pois, conhecer é praticar, mover e ser movido na ginga da resistência, do respeito e do diálogo. É conhecendo sua realidade e repensando sobre seu contexto, que através de atitudes e atividades 
problematizadora que nós assumimos como seres históricos, sociais, culturais e transformadores.

\section{CONSIDERAÇÕES FINAIS}

Podemos observar que o Programa Mais Educação visa fomentar as políticas educacionais e sociais, oferecidas gratuitamente, seguindo orientações que contemplam o espaço e tempo educacional, pautada pela noção de educação integral. Além de todas as dificuldades que se encontra no desenvolvimento do programa, seja por falta de espaço, recursos físicos e humanos, vê-se o objetivo de integração das atividades que são desenvolvidas ao projeto político-pedagógico das redes de ensino e das escolas que participam, neste caso a Escola Municipal do Calabar. É importante ressaltar a necessidade de promover conjuntamente com Secretárias ou Ministérios, em parceria, a capacitação de gestores locais, incentivar a participação das famílias, da comunidade e da sociedade civil nas atividades desenvolvidas.

Os entrevistados destacaram na oficina, o papel significativo do mestre oficineiro, o respeito, a possibilidade de estreitar laços, o sentido de grupo. Percebe-se, que por ser uma atividade de intensa expressividade, constitui-se como extremamente significativa em termos de aprendizagem e influência no comportamento e de autoestima na apropriação de sua cultura, conforme observações e conversa com os profissionais envolvidos na equipe docente. Mudanças importantes também ocorrem na interação dos participantes da oficina.

Quando o estudante conhece e pratica a capoeira entra em contato com a riqueza cultural brasileira, o aprendiz envolve-se com o todo. O respeito e o conhecimento da cultura é fundamental para o processo de inclusão e efetivação da cidadania, se fazendo pertinente e necessário a efetivação da lei 10.639/03 nas escolas. Isto nos remete a questões levantadas por Giroux (1986) ao ressaltar a necessidade de situarmos (como professores e alunos) a escola como um espaço de luta por justiça social e cultural frente a um currículo antirracista:

Todas as escolas deveriam fazer os professores e os alunos participarem do currículo antirracista que, de algum modo, está ligado a projetos da sociedade em geral. Esta abordagem redefine não somente a autoridade do professor e a responsabilidade dos alunos, mas situa a escola como uma força importante na luta por justiça social, econômica e cultural. Uma pedagogia de resistência pós-moderna e crítica pode 
desafiar as fronteiras opressivas do racismo, mas também aquelas barreiras que correm e subvertem a construção de uma sociedade democrática (GRIROUX, 1986, p. 166).

O que fica evidente ao termino desta pesquisa é que todas as propostas que são realizadas no chão da escola, devem ser levadas em consideração suas adequações às demandas locais a fim de desenvolvermos um currículo referenciado na descolonização e de rupturas culturais e epistemológicas eurocêntricas. Neste sentido, os educadores precisam em seus processos de formação, se apropriar de referências que tragam também a questão racial na educação brasileira, como aponta Gomes (2012, p. 12), multiplicando com os estudantes o respeito e o diálogo com o legado histórico da cultura afro-brasileira no desenvolvimento de nossa identidade e de nossa história.

\section{REFERÊNCIAS}

BRASIL. Constituição da República Federativa do Brasil. Brasília, DF, 1988.

. Ministério da Educação. Secretaria de Educação Continuada, Alfabetização e Diversidade. Diretoria de Educação Integral, Direitos Humanos e Cidadania. Programa Mais Educação- Passo a passo.

. Presidência da República. Casa Civil, Lei n⿳ 10.639, de 9 de janeiro de 2003. Altera a Lei ${ }^{\circ} 9.394$, de 20 de dezembro de 1996, que estabelece as diretrizes e bases da Educação Nacional, para incluir no currículo oficial da Rede de Ensino a obrigatoriedade da temática "História e Cultura Afro-Brasileira" e dá outras providências.

Caderno Pedagógico. Oficina de capoeira: A escola em movimento Fundação Cultural Palmares Jequié, 2002.

CAMPOS, Hélio (Mestre Xaréu) Capoeira na Escola. Edufba-Coleção pré-textos. Salvador-Bahia 2001.

CAMPOS JUNIOR, Pe. João de. A criança negra na escola. São Paulo: Salesianas, 1999.

CHAUÍ, Marilena. Cultura e democracia. En: Crítica y emancipación: Revista latino americana de Ciencias Sociales. Año1, no. 1 (jun. 2008- ). Buenos Aires: CLACSO, 2008 .

FREIRE, Paulo. Pedagogia da Autonomia: saberes necessários à prática educativa. Rio de Janeiro: Paz e Terra, 2007.

- Pedagogia da Esperança: um reencontro com a pedagogia do oprimido. São Paulo:Paz e Terra,1997.

. Pedagogia do Oprimido. Ed: Paz e Terra, Rio de Janeiro, 2014. 
GIROUX, Henry. Teoria crítica e resistência em educação. Rio de Janeiro: Vozes, 1986.

GOMES, N.L. Alguns termos e conceitos presentes no debate sobre relações raciais no brasil: uma breve discussão. Disponível em: $<$ http://www.acaoeducativa.org.br/fdh/wp-content/uploads/2012/10/Alguns-termos-econceitos-presentes-no-debate-sobre-Relações-Raciais-no-Brasil-uma-brevediscussão.pdf $>$ Acesso em 07 agosto de 2016.

LAKATOS, Eva Maria, Fundamentos de Metodologia Científica. 6.ed.-7 reimpr.São Paulo : Atlas 2009.

MINAYO, Maria Cecília de Souza (Org.). Pesquisa social: teoria, método e criatividade. 13 ed. Petropólis: Vozes, 2007.

MOLL, Jaqueline. Caminhos da Educação Integral no Brasil: direito a outros tempos e espaços educativos.Porto Alegre: Penso, 2012.

MUNANGA. K. Identidade, cidadania e democracia: algumas reflexões sobre os discursos anti-racistas no Brasil.In: SPINK, Mary Jane Paris(Org.) A cidadania em construção: uma reflexão transdisciplinar. São Paulo: Cortez, 1994, p. 177-187.

NASCIMENTO, Abdias. NASCIMENTO, Elisa Larkin. Africanos no Brasil: uma perspectiva Pan-Africano. Parperback, 1992.

PINTO, Álvaro Vieira. Ciência e Existência. 3. ed. Rio de Janeiro: Paz e Terra, 1979.

REIS, Letícia Vidor de S. O Mundo de Pernas para o ar- a capoeira no Brasil. São Paulo: Publisher Brasil.1997.

RÊGO, Waldeloir. Capoeira Angola: ensaio sócio-etnográfico. Salvador, Itapoã, 1968.

SANTOS, V. C. Coordenação do trabalho pedagógico: projeto político pedagógico ao cotidiano da sala de aula. $15^{\text {a }}$ Ed. São Paulo: Libertad Editora, 2013.

THIOLENT, Michel. Metodologia da Pesquisa-ação. 7 ed. São Paulo. Cortez, 1996.

TRIVIÑOS, A. N. S. Introdução à pesquisa em ciências sociais: a pesquisa qualitativa em educação. 1 ed. -22. reimpr. São Paulo, Atlas, 2013

VIEIRA, Luiz Renato. O jogo de capoeira-cultura popular no Brasil, Rio de Janeiro: SPRINT, 1999. 